\title{
Thermodynamic optimisation and computational analysis of irreversibilites in a small- scale wood-fired circulating fluidised bed adiabatic combustor
}

\author{
J. Baloyi ${ }^{1,2}$, T. Bello-Ochende ${ }^{3}$ and J.P. Meyer ${ }^{1}$ \\ ${ }^{1}$ Department of Mechanical and Aeronautical Engineering, University of Pretoria, Private \\ Bag X20, Hatfield, Pretoria, 0028, South Africa \\ ${ }^{2}$ Modelling and Digital Science, Council for Scientific and Industrial Research, P.O. Box \\ 395, Pretoria, 0001, South Africa \\ ${ }^{3}$ Department of Mechanical Engineering, University of Cape Town, Private Bag X3, \\ Rondebosch, 7701, South Africa
}

\begin{abstract}
An analysis of irreversibilities generated due to combustion in an adiabatic combustor burning wood was conducted. This was done for a reactant mixture varying from a rich to a lean mixture. A non-adiabatic non-premixed combustion model of a numerical code was used to simulate the combustion process where the solid fuel was modelled by using the ultimate analysis data. The entropy generation rates due to the combustion and frictional pressure drop processes were computed to eventually arrive at the irreversibilities generated. It was found that the entropy generation rate due to frictional pressure drop was negligible when compared to that due to combustion. It was also found that a minimum in irreversibilities generated was achieved when the Air-Fuel mass ratio was 4.9, which corresponds to an equivalence ratio of 1.64, which are lower than the respective Air-Fuel mass ratio and equivalence ratio for complete combustion with theoretical amount of air of 8.02 and 1.
\end{abstract}

\section{Keywords}

Exergy; optimisation; irriversibilities; entropy generation rate; adiabatic combustor. 


\section{Nomenclature}

\section{Abbreviation}

CFD Computational Fluid Dynamics

\section{Symbol}

a Velocity constant term $\left[\mathrm{s}^{-1}\right]$

A Cross-sectional area $\left[\mathrm{mm}^{2}\right]$

$A F \quad$ Air-Fuel mass ratio

$\bar{c} \quad$ Molar specific heat $[\mathrm{kJ} / \mathrm{kmol} . \mathrm{K}]$

c Specific heat $[\mathrm{kJ} / \mathrm{kg} . \mathrm{K}]$

$c_{p} \quad$ Specific heat at constant pressure $[\mathrm{kJ} / \mathrm{kg} . \mathrm{K}]$

C Atomic carbon

$C_{d} \quad$ One of the mixture fraction variance transport equation constant

$C_{g} \quad$ One of the mixture fraction variance transport equation constant

CO Carbon monoxide

$\mathrm{CO}_{2}$ Carbon dioxide

$\bar{f} \quad$ Mixture fraction

$\overline{f^{\prime 2}} \quad$ Mixture fraction variance 
$\vec{F} \quad$ Body force

$g \quad$ Gravitational acceleration magnitude $\left[\mathrm{m} / \mathrm{s}^{2}\right]$

$\vec{g} \quad$ Gravitational acceleration $\left[\mathrm{m} / \mathrm{s}^{2}\right]$

$\bar{h} \quad$ Specific enthalpy $[\mathrm{kJ} / \mathrm{kmol}]$

$\bar{h}^{0} \quad$ Enthalpy of formation $[\mathrm{kJ} / \mathrm{kmol}]$

$H \quad$ Atomic hydrogen; Height [mm]; total enthalpy [kJ]

$H_{2} \quad$ Molecular hydrogen

$\mathrm{H}_{2} \mathrm{O}$ Water vapour

$\hat{i} \quad$ Unit vector

I Irreversibility [W]

$k \quad$ Turbulent generate rate

$L \quad$ Length [mm]

$\dot{m} \quad$ Mass flow rate $[\mathrm{kg} / \mathrm{s}]$

$M \quad$ Molecular weight $[\mathrm{kg} / \mathrm{kmol}]$

$n \quad$ Stoichiometric coefficient

$N \quad$ Atomic nitrogen; Entropy generation number

$N_{2} \quad$ Molecular nitrogen

$O \quad$ Atomic oxygen 


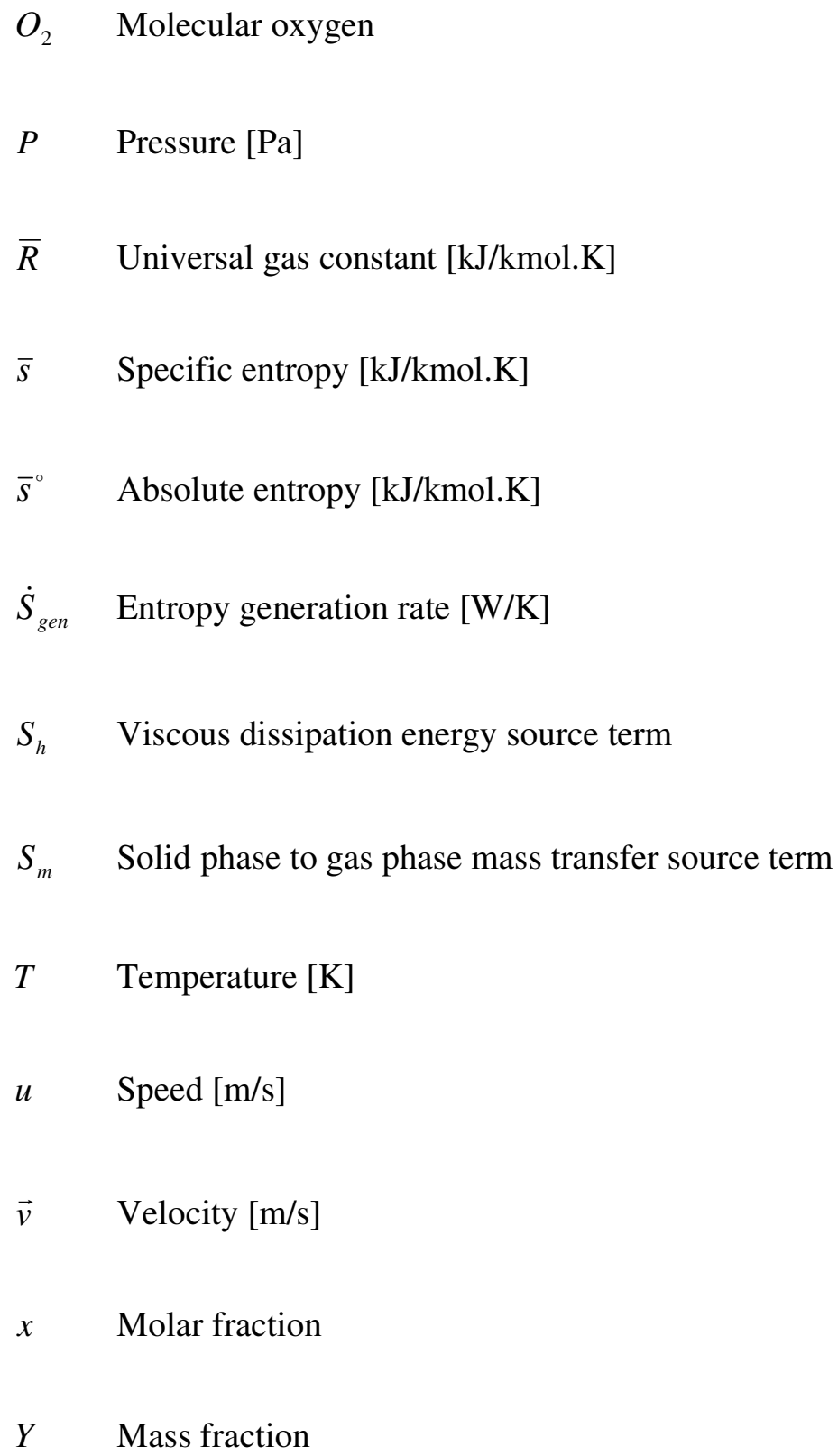

\section{Greek symbol}

$\rho \quad$ Density $\left[\mathrm{kg} / \mathrm{m}^{3}\right]$

$\varepsilon \quad$ Void fraction; turbulent dissipation rate

$\sigma_{t} \quad$ One of the mixture fraction variance transport equation constant

$\mu \quad$ Molecular viscosity [Pa.s] 


$$
\begin{array}{ll}
\mu_{t} & \text { Turbulent viscosity [Pa.s] } \\
\overline{\bar{\tau}} & \text { Stress tensor }
\end{array}
$$

\section{Subscript}

$0 \quad$ Superficial

Air Air

char Char

$\mathrm{CO}$ Carbon monoxide

$\mathrm{CO}_{2}$ Carbon dioxide

$f \quad$ Fuel

$g \quad$ Gas

gen, $\min \quad$ Minimum entropy generation rate

gen $(h) \quad$ Entropy generation rate due to heat

$\operatorname{gen}(p) \quad$ Entropy generation rate due to frictional pressure drop

$H_{2} \quad$ Molecular hydrogen

$\mathrm{H}_{2} \mathrm{O}$ Water vapour

$i \quad$ Counting index

$l \quad$ Maximum number of products

$m \quad$ Maximum number of reactants; mixture 


$\begin{array}{ll}m f & \text { Minimum fluidisation } \\ N_{2} & \text { Molecular nitrogen } \\ O_{2} & \text { Molecular oxygen } \\ p & \text { Product species } \\ r & \text { Reactant species } \\ r e f & \text { Environment reference } \\ s & \\ s & \text { Solid species } \\ s d & \text { Dense zone solid species } \\ t h & \\ & \end{array}$

\section{Introduction}

Incomplete combustion process of solid fuels such as those found in circulating fluidised bed combustors are difficult to model as compared to complete combustion [1]. The reason for this is that for complete combustion the proportion of each combustion product can easily be predicted analytically through the stoichiometric equation $[1,2,3,4]$, whereas this cannot be the case for incomplete combustion. This makes it hard to predict the performance of a combustion unit as measured against desired output. The Air-Fuel mass ratio (AF) can be selected such that combustion occurs, but for incomplete combustion the proportions of the combustion products cannot be predicted analytically as mentioned earlier. For an incomplete 
combustion process the combustion products mixture will contain unburnt fuel in the form of char and maybe volatile gases released from the devolatilisation of the solid fuel. There is negligible molecular oxygen in the combustion products mixture $[1,2,3,4]$. In the case of complete combustion with excess air there will be molecular oxygen in the combustion mixture, but there will not be any fuel components that resulted from the devolatilisation process [1], assuming proper mixing occurred. Because the combustor is adiabatic the total enthalpy across it does not change, but entropy increases [1]. A way to alleviate this predicament is to conduct experiments or run numerical simulations that predict the proportion of each combustion product. Elfasakhany et al. [5] undertook experimental and numerical studies to find reasons for emissions of unburned volatiles and particles of pulverised wood in combustion products mixture, and they found that the emissions were sensitive to fuel particle size and combustor configuration. Different AF ratios will results in different exergies or availability of the energy released as measured by means of a combustion products average temperature. Chen et al. [6] compared the gasification of raw biomass, torrefied biomass and coal using pure oxygen, and found that there is an optimum oxygen-fuel ratio for each fuel at which gasification is most efficient. Tran et al. [7] found that torrefaction of stump biomass resulted in increased heating values and grind-ability of the fuel when compared to untreated biomass, but terrofaction made the treated fuel less reactive. Zhang et al. [8] experimented on gasification of caking coal in a pilot fluidised bed gasifier, where they found that the optimal proportion of oxygen used for pre-oxidation of $37 \%$ of the total oxygen supply greatly enhanced the gasification rate. The availability of the energy released from the combustion process can be quantified through the computation of an entropy generation rate as given Bejan [9]. Le Roux, Bello-Ochende and Meyer [10] used the technique of total entropy generation minimisation to find the optimum operating point of a turbine, and to optimise the geometric parameters of a recuperator and receiver of an open 
and direct solar thermal Brayton cycle. Mwesigye, Bello-Ochende and Meyer [11] numerically investigated the entropy generation rate due to heat transfer and fluid friction in a parabolic trough receiver. They found that a minimum entropy generate rate existed for every combination of concentration ratio and inlet temperature, which corresponds to an optimum flow rate. Le Roux, Bello-Ochende and Meyer [12] used the dynamic trajectory optimisation method to find optimised geometric parameters, minimum irreversibility rates and maximum receiver surface temperatures for an open and direct solar thermal Brayton cycle. For an adiabatic circulating fluidised bed combustor the entropy generation rate is due to frictional pressure loss across the combustor and the combustion process. The frictional pressure drop across a conduit for a fluidised system as given by Kunii and Levenspiel [13] remains the same once minimum fluidisation has been attained. Gupta and Reddy [14] analysed the effect of pressure on the bed-to-wall heat transfer in a pressurised circulating fluidised bed riser by modifying a cluster renewal model developed for atmospheric circulating fluidised bed riser columns. The model they developed agreed well with experimental results and literature. Han et al. [15] found that pressurisation improved the capture of $\mathrm{CO}_{2}$ when using $\mathrm{CaO}$ in a fluidised bed gasifier of sawdust. Aisyah, Ashman and Kwong [16] found that coal fly-ash oxygen carriers were effective in converting carbon dioxide into carbon monoxide when used in chemical looping combustion of synthesis gas. Aghbalou, Badia and Illa [17] conducted an exergetic optimisation of a solar collector and thermal storage system where they used a phase change material. The optimisation resulted in an analytical model that compared well to experimental data they generated a priori. Kousksou et al [18] conducted a second law analysis of latent thermal storage for a solar system where they studied the behaviour of phase change material in the form of its melting temperature. Exergy analysis of phase change materials was also conducted by Li et al [19] where they developed a mathematical model for the thermal storage of energy from a solar collector system. They developed the 
model based on the finite-time thermodynamics method. A review of exergy based performance evaluation of phase change materials latent heat thermal storage systems was performed by Jegadheeswaran, Pohekar and Kousksou [20] where they looked at the influence of design parameters and operating conditions on optimisation of the thermal storage systems. Brandvoll and Bolland [21] used exergy analysis on results from simulations to show that a chemical looping combustion process has lower irreversibilities than a conventional combustion process with air. Srinivas et al [22] performed energy and exergy analyses of pressurised and atmospheric circulating fluidised bed char combustion units where they identified the pressure ratio and maximum value of the gas turbine inlet temperature as the parameters that have a dominant impact on the combined cycle plant performance. The exergy efficiency of a blast furnace process was found to have high exergy efficiency, but the compressing and preheating of the blast was found to be characterised by high exergy losses due to the associated combustion process in a study conducted by Ziebik and stanek [23]. Ziebik and stanek [24] also looked at the thermal improvement of a blast furnace process through the increase of blast temperature and its oxygen enrichment. They did this through energy and exergy analyses. Nur Izyan and Shuhaimi [25] used exergy analysis on a crude oil distillation unit to find strategies to reduce fossil fuel depletion problem, they found that the first inlet furnace had the highest exergy loss and that the best strategies are to reduce the heat loss from furnace stack and an overall cleaning schedule of crude preheat train. Gupta and Reddy [26] performed energy and exergy analyses on a combined-cycle power plant all in the aim of modernising the plant. They found that the combustion chamber, gas turbines and heat recovery steam generators were the main sources of irreversibilities. The irreversibilities of Proton Exchange Membrane fuel cells were analysed by Cihan, Hacihafizoglu and Kahveci [27] as a function of operating pressure, pressures of the electrodes, current density, etc. Bapat, Majali and Ravindranath [28] did an 
exergetic evaluation of two quintuple effect evaporators with and without heat recovery, and found that an increase in exhaust inlet temperature results in deterioration in exergetic performance of the evaporator with heat recovery and the quality of end product. Ghazikhani et al. [29] used a double pipe heat exchanger with counter current flow to recover exergy by cooling the exhaust from a diesel engine. They found that the recovered exergy increased with increasing load and engine speed. They also found that when they used the recovered exergy, the brake specific fuel consumption decreased markedly. Ghazikhani et al. [30] investigated the improvement in performance and reduction in emissions due to ethanol additives in a two stroke SI engine. They found that there is a reduction in brake specific fuel consumption and there is a reduction in pollutants emitted, with a $35 \%$ reduction in $\mathrm{CO}$ emission being the highest. In a related paper Gazikhani, Hatami and Safari [31] found that for $5 \%$ added ethanol into the fuel the second law efficiency was higher for 2500 and 3000 revolutions per minute settings. Chintala and Subramanian [32] used an exergy analysis on a hydrogen-diesel engine to determine the maximum available work and irreversibility due to mixing, combustion, unburned and friction. They found that the maximum available work increased with $\mathrm{H}_{2}$ addition due to reduction in irreversibility due to combustion. They also found that the addition of $H_{2}$ had no effect on the irreversibility due to friction and mixing, whereas the irreversibility due to unburned fuel decreased due to the high temperature combustion that result with the addition of $H_{2}$. Jafarmadar [33] found that even though the exergy efficiency decreased when they increased the mass fraction of exhaust gas recirculation in an indirect injection diesel engine from $0 \%$ to $30 \%$, the cumulative irreversibility in the combustion chamber decreased. Ting, Hung and Guo [34] investigated the entropy generated by nanofluid with streamwise conduction in microchannels. They found that there existed minimal entropy generation at certain range of the low-Peclet number flow regime. The need to combat rise in $\mathrm{CO}$ and $\mathrm{CO}_{2}$ emissions from coal combustion has 
put pressure on utilities and governments of countries where the main source of electricity is from coal combustion. Substitutes for coal combustion that can result in lower emissions of $\mathrm{CO}$ and $\mathrm{CO} 2$ are some of the mitigation solution under consideration at the moment. These substitutes can be complete replacement of coal with wood as a source of heat in a boiler or a blending of wood with coal. However combustors usually do not completely burn the solid fuel, especially circulating fluidised combustors. In order to investigate the viability of wood as a source of heat in a typical combustor setting, the analysis of irreversibilities generated during the combustion of pitch pine in an adiabatic circulating fluidised bed combustor was conducted as the Air-Fuel mass ratio was varied to achieve a reactant mixture varying from a rich mixture to a lean mixture. This was achieved by fixing the fuel mass flow rate at one value, but we reduced or increased the air mass flow rate.

\section{Mathematical Model}

The study was of an adiabatic combustor burning pitch pine wood as illustrated in Fig. 1. The adiabatic combustor consisted of a cylinder with an adiabatic wall, inlets for the solid fuel and primary air inlet for the air used to devolatilise the solid fuel and secondary air inlets if needed to complete the combustion of the fuel. The different states of complete/incomplete combustion were attained by changing the mass flow rate of the incoming oxidising air, thereby varying the AF. The chemical formula of the solid fuel as computed in [1] is given by $\mathrm{C}_{4.9} \mathrm{H}_{7.2} \mathrm{O}_{2}$.

The lower heating value of the fuel from [1] was given as $16091.2 \mathrm{~kJ} / \mathrm{kg}$ and the molecular weight of the fuel was calculated as $98 \mathrm{~kg} / \mathrm{kmol}$. The specific heat at constant pressure was also given as $1.680 \mathrm{~kJ} / \mathrm{kg} . \mathrm{K}$. 


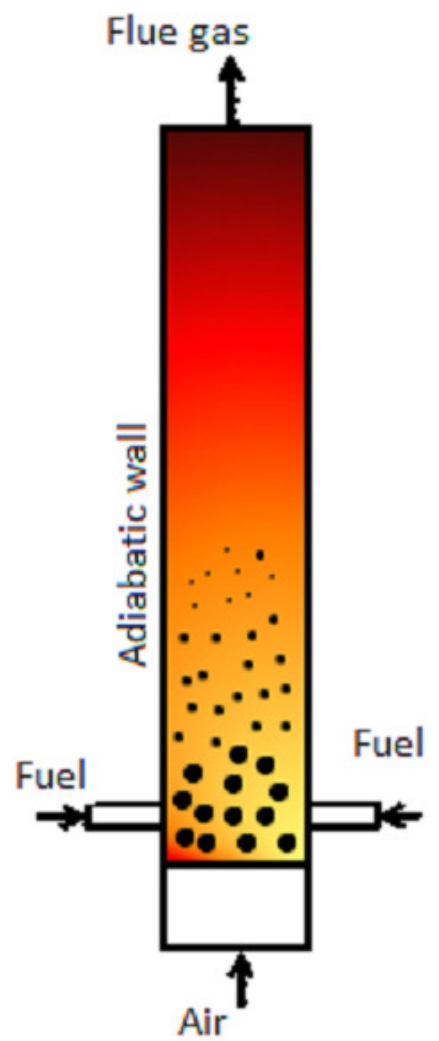

Fig. 1. Schematic of an adiabatic combustor (adopted from [1]).

The availability of the energy released from the combustion process was analysed for scenarios on both sides of the theoretical air complete combustion point, i.e. the incomplete combustion with air deficiency and complete combustion with excess air. Complete combustion of pitch pine wood occurs at an AF of 8.02 as was determined in [1]. The availability was analysed as a function of AF.

\subsection{Exergy analysis}

The irreversibility generation rate that results from the combustion and frictional pressure drop processes taking place in an adiabatic combustor is as given by Eq. (1)

$$
\dot{I}=\frac{\dot{m}_{f}}{M_{f}}\left(\sum_{i=1}^{m} n_{r i}\left(\bar{h}-T_{r e f} \bar{s}\right)_{r i}-\sum_{i=1}^{l} n_{p i}\left(\bar{h}-T_{r e f} \bar{s}\right)_{p i}\right)
$$


Since the enthalpy terms cancel out in Eq. (1), the irreversibility generation rate can also be defined, by Eq. (2)

$\dot{I}=T_{r e f} \dot{S}_{g e n}$

Where $\dot{S}_{g e n}$ is the entropy generation rate. The specific entropy is given by Eq. (3).

$\bar{s}_{p i}=\bar{s}_{p i}^{\circ}(T)-\bar{R} \ln \left(P x_{p i} / P_{r e f}\right)$

The static pressure in the combustor is the same as the reference static pressure, i.e. $P=P_{r e f}$, and the molar fraction of each product species, $x_{p i}$, is given by Eq. (4)

$x_{p i}=n_{p i} / \sum_{i=1}^{l} n_{p i}$

$n_{p i}$ is the stoichiometric coefficient of combustion product species $i$. The same expressions

apply for reactants. $\bar{h}$ is the specific enthalpy, $\bar{s}_{p i}^{\circ}$ is the absolute entropy, $\bar{R}$ is the universal gas constant, $p$ is the static pressure, $P_{r e f}$ is the reference static pressure of the environment and $T_{r e f}$ is the reference temperature of the environment. . The specific entropy of the solid fuel was computed by defining [1] it as given by Eq. (5).

$\bar{s}=\bar{c} \ln \left(T_{f} / 298\right)$

$\bar{c}$ is the molar specific heat of the solid fuel.

The entropy generation rate $\dot{S}_{g e n}$ is due to the combustion and the pressure drop phenomena. Generally the entropy generation rate term is not defined in detail in terms of its constituents. In section 2.1.1. we give the detailed expressions of the entropy generation rate term constituents.

\subsubsection{Entropy generation rate}

Entropy generation rate is a term that can be used to quantify the inefficiencies of thermodynamic systems as they convert energy from one form to another. Complete elimination of this term is not possible for real systems; however its minimisation could result 
in maximisation of the exergy available from these systems and hence improved efficiencies. The entropy generation rate term due to combustion was defined [9] in terms of the change in entropy of the system due to reactions. On the other hand the entropy generation rate due to frictional pressure drop was defined in terms of the pressure drop of the system [9]. Each of the two terms was defined and derived in turn as presented below.

\subsubsection{Friction pressure drop entropy generation rate}

The friction pressure drop entropy generation rate term is made up of the contribution due to the air-fuel mixture as it flows through the riser. The contribution due to the air-fuel mixture flow is given by Eq. (6).

$$
\dot{S}_{g e n(p)}=\frac{\dot{m}_{t} \Delta P}{\rho_{m} T_{m}}
$$

$\Delta P$ is the pressure drop across the combustor, $\dot{m}_{t}$ is the total air and fuel mass flow rate, $\rho_{m}$ is the mixture density, $T_{m}$ is the mixture temperature. The pressure drop across the riser due to the air-fuel mixture [13] is given by Eq. (7).

$\Delta P=L_{m f}\left(1-\varepsilon_{m f}\right)\left(\rho_{f}-\rho_{g}\right) g$

$\varepsilon_{m f}$ is the minimum fluidisation solid volume fraction, $\rho_{f}$ is the char density, $\rho_{g}$ is the gaseous density, $L_{m f}$ is the minimum fluidisation height and $g$ is acceleration due to gravity. The pressure drop can also be expressed in terms of the total height of the riser by using an expression found in [13] for an air-solid mixture undergoing fast fluidisation inside a vertical column as given by Eq. (8).

$$
L_{m f}\left(1-\varepsilon_{m f}\right)=\frac{\varepsilon_{s d}-\varepsilon_{s e}}{a}+H_{t} \varepsilon_{s d}-H_{f}\left(\varepsilon_{s d}-\varepsilon_{s}^{*}\right)
$$


$\mathcal{E}_{s d}$ is the solid volume fraction in the bed region of the riser, $\varepsilon_{s e}$ is the solid volume fraction at the exit of the riser, $a$ is an empirical velocity term, $H_{t}$ is the total height of the riser, $H_{f}$ is the freeboard height and $\varepsilon_{s}^{*}$ is the minimum value that $\varepsilon_{s e}$ can assume. Kunii and Levenspiel [13] also give an expression for $H_{f}$ as given by Eq. (9).

$H_{f}=\left[\ln \left(\varepsilon_{s d}-\varepsilon_{s}^{*}\right)-\ln \left(\varepsilon_{s e}-\varepsilon_{s}^{*}\right)\right] / a$

When Eqs. (7 - 9) are substituted into Eq. (6), the pressure drop is eliminated and results in an expression as given by Eq. (10).

$\dot{S}_{g e n(p)}=\frac{\dot{m}_{t}\left(\rho_{f}-\rho_{g}\right) g\left[\frac{\varepsilon_{s d}-\varepsilon_{s e}}{a}+H_{t} \varepsilon_{s d}+\ln \left(\frac{\varepsilon_{s e}-\varepsilon_{s}^{*}}{\varepsilon_{s d}-\varepsilon_{s}^{*}}\right)\left(\frac{\varepsilon_{s d}-\varepsilon_{s}^{*}}{a}\right)\right]}{\left(\varepsilon_{s e} \rho_{f}+\left(1-\varepsilon_{s e}\right) \rho_{g}\right) T_{m}}$

The mixture density was computed as expressed by Eq. (11).

$\rho_{m}=\varepsilon_{s e} \rho_{f}+\left(1-\varepsilon_{s e}\right) \rho_{g}$

The empirical velocity term $a$ can be expressed in terms of the fuel mass flow rate and the AF. Firstly the empirical velocity term is given by $a=10 / u_{0}$, where $u_{0}$ is the superficial velocity. But the superficial velocity is given as $u_{0}=\left(1-\varepsilon_{s d}\right) u_{g}$, where $u_{g}$ is the gas velocity. The gas velocity in turn is expressed as Eq. (12)

$u_{g}=\dot{m}_{g} / \rho_{g} A$

Given the fact that the total mass flow rate is expressed by Eq. (13), and that the Air-Fuel mass ratio is expressed as $A F=\dot{m}_{g} / \dot{m}_{f}$, the superficial velocity can be written as expressed by Eq. (14).

$\dot{m}_{t}=\dot{m}_{g}+\dot{m}_{f}$ 
$u_{0}=\left(1-\varepsilon_{s d}\right) \frac{\dot{m}_{f} A F}{\rho_{g} A}$

Hence the empirical velocity term can be expressed in terms of the fuel mass flow rate and $\mathrm{AF}$ as given by Eq. (15).

$a=\frac{10 \rho_{g} A}{\left(1-\varepsilon_{s d}\right) \dot{m}_{f} A F}$

When Eq. (15) is substituted into Eq. (10), the entropy generation rate due frictional pressure can be expressed in terms of the fuel mass flow rate and AF as given by Eq. (16).

$\dot{S}_{g e n(p)}=\frac{\dot{m}_{f}(A F+1)\left(\rho_{f}-\rho_{g}\right) g\left[\frac{\left(\varepsilon_{s d}-\varepsilon_{s e}\right)\left(1-\varepsilon_{s d}\right) \dot{m}_{f} A F}{10 \rho_{g} A}+H_{t} \varepsilon_{s d}+\ln \left(\frac{\varepsilon_{s e}-\varepsilon_{s}^{*}}{\varepsilon_{s d}-\varepsilon_{s}^{*}}\right)\left(\frac{\varepsilon_{s d}-\varepsilon_{s}^{*}}{10 \rho_{g} A}\right)\left(1-\varepsilon_{s d}\right) \dot{m}_{f} A F\right]}{\left(\varepsilon_{s e} \rho_{f}+\left(1-\varepsilon_{s e}\right) \rho_{g}\right) T_{m}}$

\subsubsection{Combustion entropy generation rate}

The entropy generation rate due to the combustion process is given by Eq. (17).

$\dot{S}_{g e n(h)}=\frac{\dot{m}_{f} \Delta \bar{s}}{M_{f}}$

The change in entropy $\dot{S}_{g e n(h)}$ accounts for the increase in entropy as the fuel is oxidised by the oxygen in the air. The change in entropy is constituted by contributions from gaseous species and solid species, i.e. $\Delta \bar{s}=\Delta \bar{s}_{g}+\Delta \bar{s}_{s}$. The contribution to the entropy change from gaseous species is given by Eq. (18).

$\Delta \bar{s}_{g}=\sum_{j=1}^{l} n_{p j}\left(\bar{s}^{\circ}-\bar{R} \ln (x)\right)_{P j}-\sum_{j=1}^{m} n_{r j}\left(\bar{s}^{\circ}-\bar{R} \ln (x)\right)_{r j}$ 
$M_{j}$ is the molecular weight of species $j$. The contribution to the entropy change from solid species is as expressed by Eq. (19).

$\Delta \bar{s}_{s}=\frac{\rho_{\text {char }}}{\rho_{g}} n_{\text {char }} c_{\text {char }} M_{\text {char }} \ln \left(T_{\text {char }} / 298\right)-\frac{\rho_{f}}{\rho_{g}} n_{f} c_{f} M_{f} \ln \left(T_{f} / 298\right)$

$c_{c h a r}$ is the specific heat constant for the char particles and $c_{f}$ is the specific heat constant for the solid fuel. When Eqs. (18) and (19) are substituted into Eq. (17) the entropy generation rate due to combustion can be expressed as given by Eq. (20).

$\dot{S}_{g e n(h)}=\frac{\dot{m}_{f}}{M_{f}}\left(\begin{array}{l}\sum_{j=1}^{l} n_{p j}\left(\bar{s}^{\circ}-\bar{R} \ln (x)\right)_{P j}-\sum_{j=1}^{m} n_{r j}\left(\bar{s}^{\circ}-\bar{R} \ln (x)\right)_{r j}+\frac{\rho_{c h a r}}{\rho_{g}} n_{c h a r} c_{c h a r} M_{c h a r} \ln \left(T_{\text {char }} / 298\right) \\ -\frac{\rho_{f}}{\rho_{g}} n_{f} c_{f} M_{f} \ln \left(T_{f} / 298\right)\end{array}\right)$

\subsubsection{Entropy generation number and relative entropy generation rate}

The entropy generation rate at any equivalence ratio was analysed further by means of two ratios. An equivalence ratio of 1 means complete combustion with theoretical amount of air, whereas an equivalence ratio above 1 signifies a rich mixture and that below 1 signifies a lean mixture. The first ratio is the entropy generation number, $N_{s}$ [9] which is the quotient of the entropy generation rate at any equivalence ratio and the minimum entropy generation rate, and is as given by Eq. (21).

$$
N_{s}=\frac{\dot{S}_{g e n}}{\dot{S}_{g e n, \min }}
$$

Since $\dot{S}_{g e n, \min }$ is the best possible solution at which the most exergy can be generated, $N_{s}$ measures the penalty paid in terms of lost exergy when deviating far from the point where minimum entropy generate rate occurs. The second ratio is relative generation rate, which is 
the quotient of the entropy generation rate at any equivalence ratio and the entropy generation rate when combustion occurred with theoretical air ratio, and is as expressed by Eq. (22).

$N_{R}=\frac{\dot{S}_{g e n}}{\dot{S}_{\text {gen, th }}}$

$\dot{S}_{\text {gen,th }}$ measures the entropy generation rate when complete combustion occurs with theoretical amount of air. This point also happens to be where maximum possible temperature can be achieved. So $N_{R}$ can be a measure of gained or lost efficiency by sacrificing attainment of the maximum possible temperature in order to maximise exergy generation.

\subsection{CFD model}

The adiabatic combustor produced $241 \mathrm{~kW}_{\text {th }}$ when complete combustion of pitch pine wood occurs with theoretical amount of air. The combustor had a diameter of $300 \mathrm{~mm}$ and a height of $7000 \mathrm{~mm}$ as illustrated in Fig. 2. 


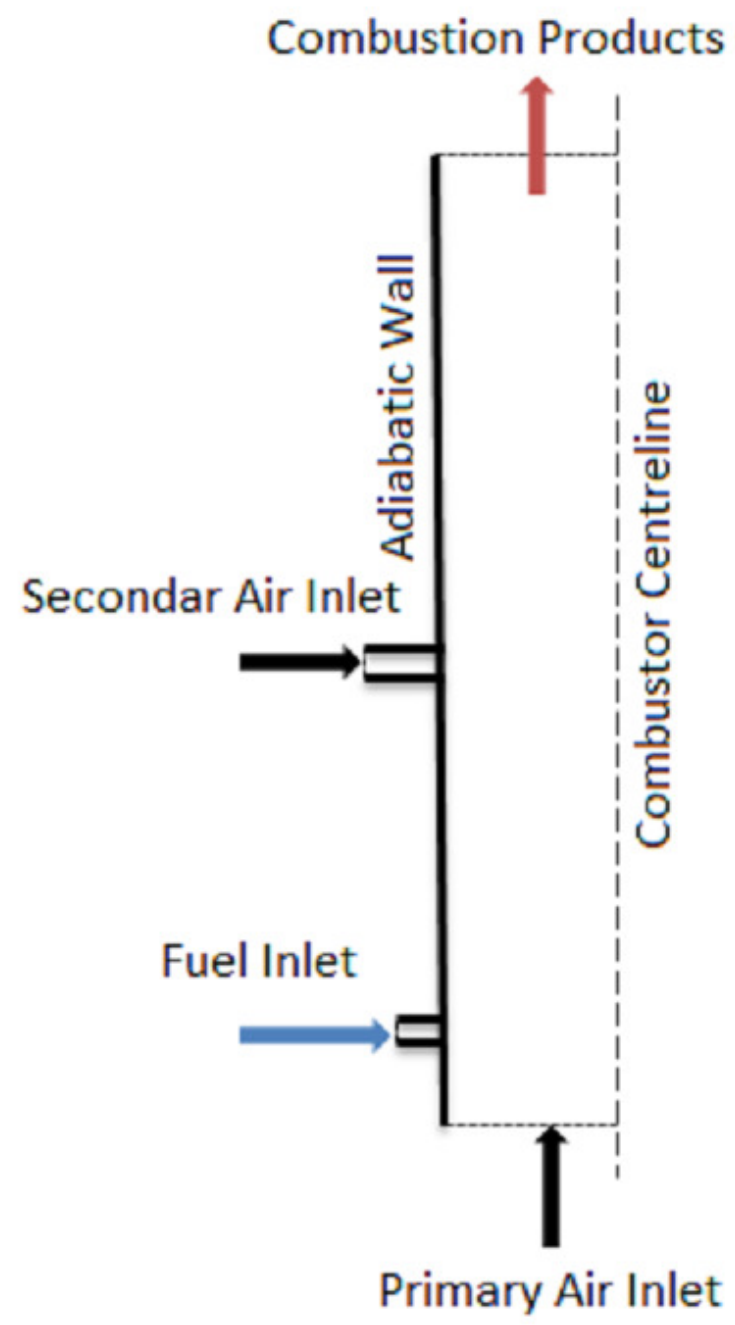

Fig. 2. Schematic of the adiabatic combustor showing boundary placements.

The mass flow rate of the incoming solid fuel was fixed at a value of $0.015 \mathrm{~kg} / \mathrm{s}$ so as to have a common maximum heat generation rate of $241 \mathrm{~kW}_{\text {th }}$ since the lower heating value is fixed and unique for any particular fuel. ANSYS Fluent 14 [35] was used to simulate the combustion process inside the adiabatic combustor. The combustion process was modelled using the non-premixed combustion model because the solid fuel is only specified in ultimate analysis data as given in Table 1, and the combustion model gives an option of specifying the fuel as an empirical stream. The inlet diffusion option was selected. 


\section{Table 1}

Pitch pine ultimate analysis data (adapted from [36]).

\begin{tabular}{cc}
\hline Element & Value \\
\hline $\mathrm{C}$ & $59.0(\%)$ \\
$\mathrm{H}$ & $7.2(\%)$ \\
$\mathrm{O}$ & $32.7(\%)$ \\
Ash & $1.13(\%)$ \\
$\mathrm{HHV}$ & $24220(\mathrm{~kJ} / \mathrm{kg})$ \\
LHV & $16091.2(\mathrm{~kJ} / \mathrm{kg})$ \\
Molecular & $98(\mathrm{~kg} / \mathrm{kmol})$ \\
weight & \\
\hline
\end{tabular}

The continuity and momentum equations [35] as expressed by Eq. (23) and Eq. (25) respectively were solved for under steady state condition.

$$
\begin{aligned}
& \nabla \cdot(\rho \vec{v} \bar{f})=\nabla \cdot\left(\frac{\mu_{t}}{\sigma_{t}} \nabla \bar{f}\right)+s_{m} \\
& \nabla \cdot\left(\rho \vec{v} \overline{f^{\prime 2}}\right)=\nabla \cdot\left(\frac{\mu_{t}}{\sigma_{t}} \nabla \overline{f^{\prime 2}}\right)+C_{g} \mu_{t}(\nabla \bar{f})^{2}-C_{d} \rho \frac{\varepsilon}{k} \overline{f^{\prime 2}} \\
& \nabla \cdot(\rho \vec{v} \vec{v})=-\nabla p+\nabla \cdot(\overline{\bar{\tau}})+\rho \vec{g}+\vec{F}
\end{aligned}
$$

The stress tensor [30] is given by Eq. (27).

$$
\overline{\bar{\tau}}=\mu\left[\left(\nabla \vec{v}+\nabla \vec{v}^{T}\right)-\frac{2}{3} \nabla \cdot \vec{v} \hat{i}\right]
$$

$\mu$ is the molecular viscosity of the continuous phase, $\vec{F}$ is the interactive body forces between the dispersed and the continuous phases, $S_{m}$ is the source term accounting for the mass transfer from the solid phase to the gas phase and $\hat{i}$ is a unit vector. $\bar{f}$ and $\overline{f^{\prime 2}}$ are the mixture fraction and its variance, and are computed by applying an assumed shape probability density function ( $\beta$-function) when modelling the turbulence-chemistry interaction.

The energy for the non-premixed combustion model [35] was as expressed by Eq. (27).

$$
\nabla \cdot(\rho \vec{v} H)=\nabla \cdot\left(\frac{k_{t}}{c_{p}} \nabla H\right)+S_{h}
$$

The total enthalpy $H$ is given by Eq. (28). 
$H=\sum_{j=1}^{m} Y_{j} \int_{T_{r e f, j}}^{T}\left(c_{p, j} d T+h_{j}^{0}\left(T_{r e f, j}\right)\right)$

$Y_{j}$ is the mass fraction, $c_{p, j}$ is the specific heat and constant pressure and $h_{j}^{0}\left(T_{r e f, j}\right)$ is the enthalpy of formation of the $j^{\text {th }}$ species. $S_{h}$ is the source term due to viscous dissipation. The use of the chosen combustion model required the use of a turbulent model because the combustion model is a mixture model. To this end the $k-\varepsilon$ turbulent model with enhanced wall function option was chosen for all simulations. 


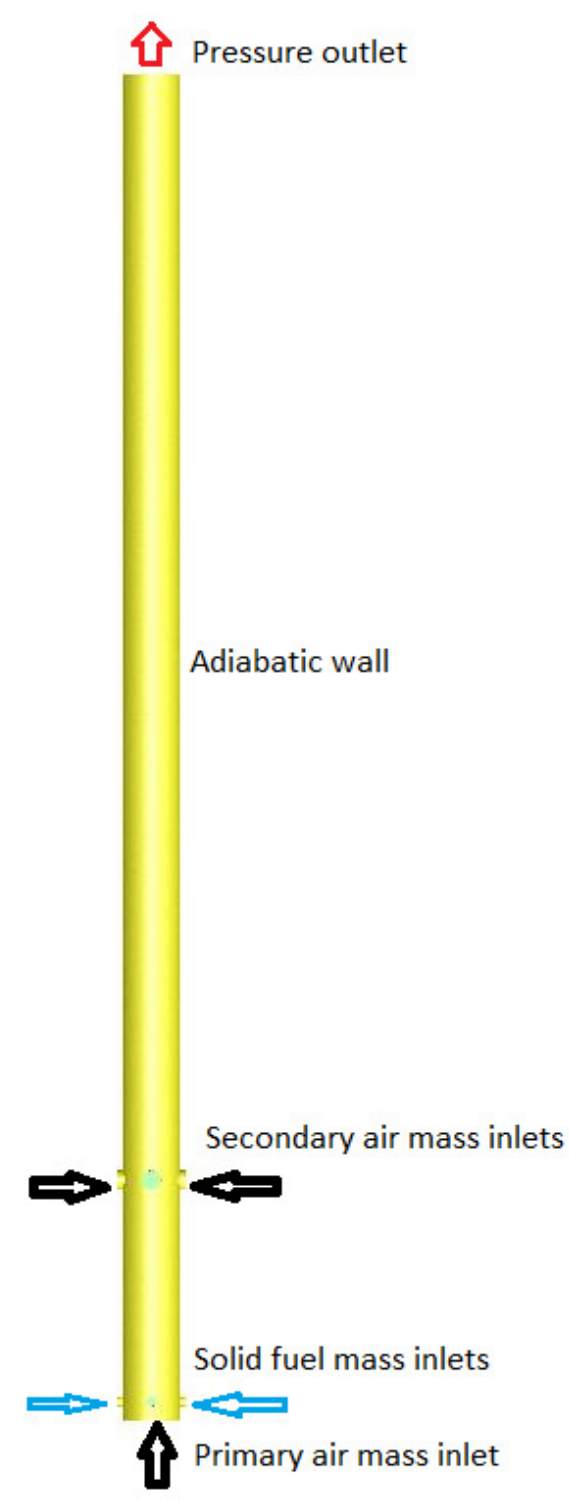

Fig. 3. Schematic of the geometry used in Ansys Fluent 14 to model the adiabatic combustor.

The adiabatic combustor had four mass flow inlets for the solid fuel as shown in Fig. 3, each with equal mass flow rate of $0.00375 \mathrm{~kg} / \mathrm{s}$. The inlet temperature of the fuel at each inlet was set at $600 \mathrm{~K}$. The temperature value was selected to be same as the devolatilisation temperature of pitch pine [36]. The oxidising air was split into the primary and secondary air, each making up half of the total air used in the oxidation of the fuel. The reason for splitting the oxidising air was to enable the modelling of incomplete combustion to take place. The 
primary air entered the combustor at the base with a single fixed mass inlet, with half of the total air mass flow rate. The secondary air four fixed mass inlets were situated a quarter of the height up the combustor, each having an eighth of the total air mass flow rate. The inlet temperature at all eight air inlets was set at $298 \mathrm{~K}$. The wall of the combustor was adiabatic. The data that was extracted from the simulations were the temperature at the pressure outlet boundary and the combustion products molar fractions. Fig. 3 shows the placement and types of boundaries applied on the combustor.

Mesh independence of the solution was carried out for different mesh cell numbers. The Figure of merit used to quantify mesh independence was $\Delta$, which was used to quantify the change in entropy generation rate as the number of cells in the computation domain was increased. The entropy generation rate was computed for the case of complete combustion with theoretical amount of air. It was computed as $\Delta=\left(\dot{S}_{g e n, i}-\dot{S}_{g e n, i-1}\right) / \dot{S}_{g e n, i-1}$, and the results are tabulated in Table 2.

Table 2

Mesh independence analysis results.

\begin{tabular}{crc}
\hline Number of cells & $\dot{S}_{g e n}(\mathbf{W} / \mathbf{K})$ & $\Delta(\%)$ \\
\hline 438192 & 362.6218 & \\
609857 & 362.6756 & $0.01 \%$ \\
655783 & 362.7186 & $0.01 \%$ \\
747055 & 364.1874 & $0.40 \%$ \\
1188339 & 361.6429 & $-0.70 \%$ \\
\hline
\end{tabular}

The mesh used for the numerical simulations had 747055 unstructured polyhedral cells. The Presto scheme was used to solve for pressure and second-order upwind schemes were used to solve for the continuity, energy, turbulence and mass fraction. The results obtained when using Eq. (16) and Eq. (20) to process data from CFD simulations and data from thermodynamics tables data [2] were compared for the case of complete combustion with 
varying amount of excess air, that is lean mixtures. It was found that the results from CFD data compared well with results from thermodynamics tables data as shown in Fig. 4.

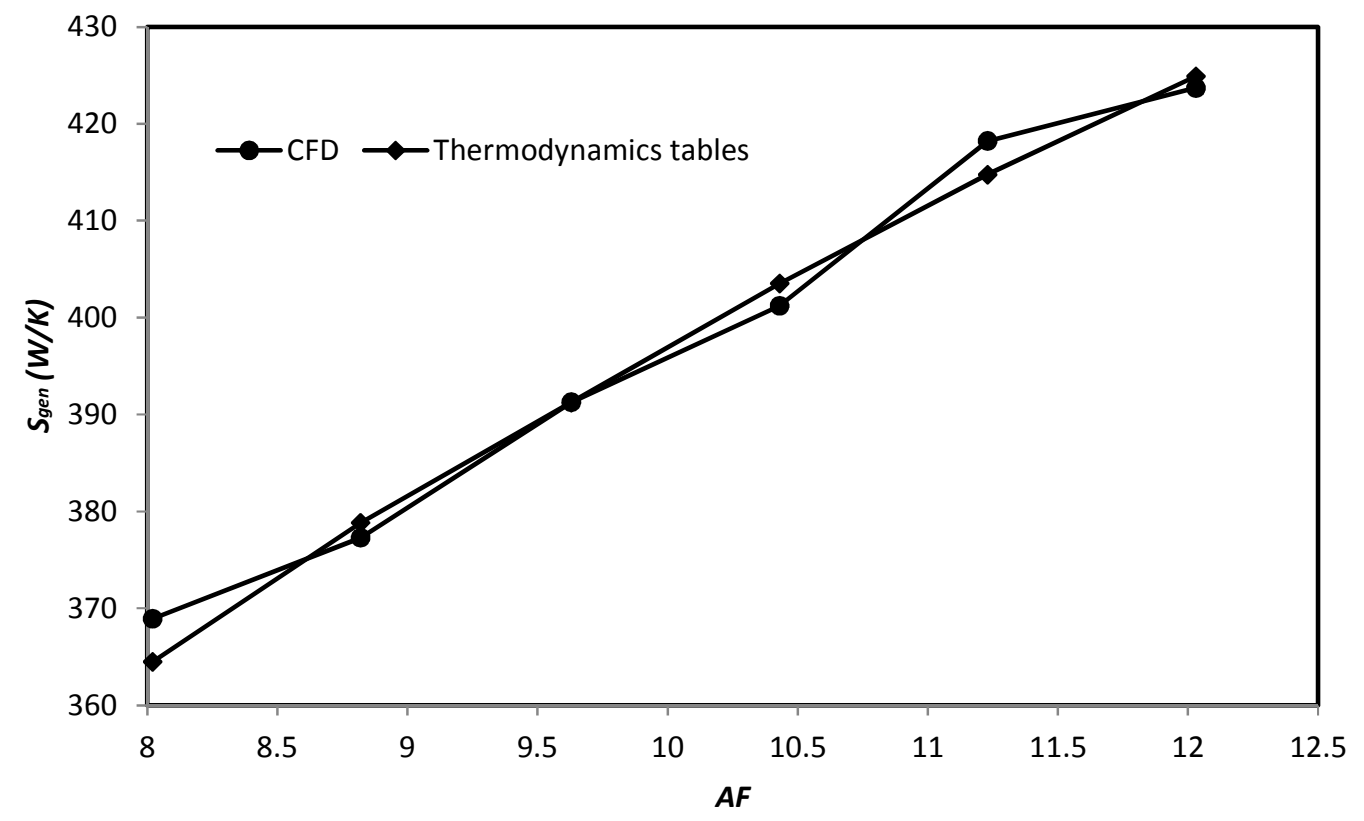

Fig. 4. The entropy generation rate profile as a function of $\mathrm{AF}$ in an adiabatic combustor for lean mixtures.

\section{Results and discussion}

The entropy generation rate was almost entirely due to the combustion process, with negligible contribution from the component from frictional pressure drop as can be seen from Fig. 5. 


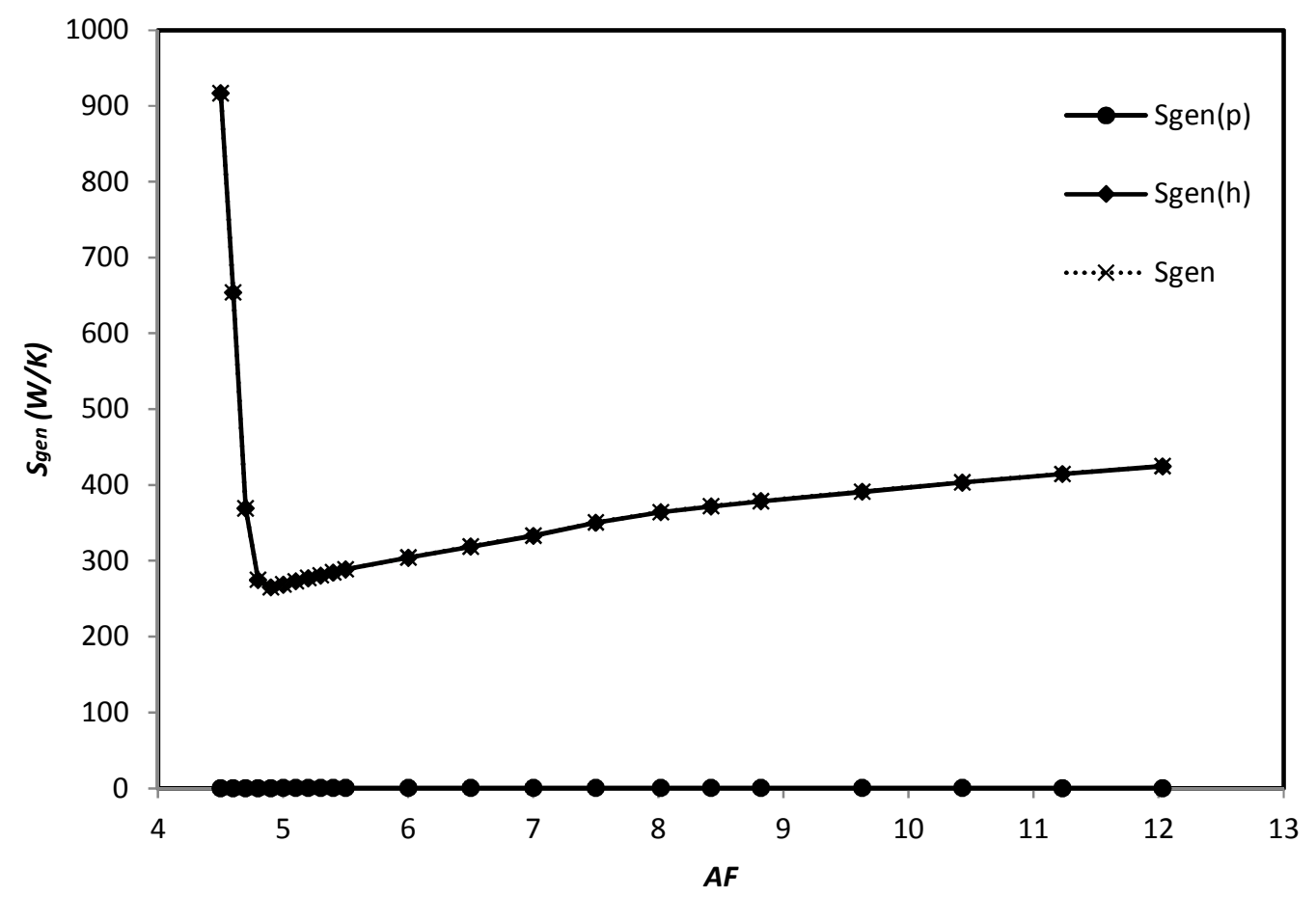

Fig. 5. The entropy generation rate profile as a function of AF in an adiabatic combustor.

The change in the entropy generation rate as a function of AF was plotted as shown in Fig. 6 . The figure shows that the entropy generation rate reaches a minimum at an AF of 4.9. This is well illustrated by the close up plot as shown by Fig. 7. This ratio occurs when there is incomplete combustion inside the adiabatic combustor as complete combustion with theoretical amount of air occurs at 8.02. Fig. 6 also shows the variation of the generated irreversibities with $\mathrm{AF}$, which were computed from the entropy generation rate as given by Eq. (2). 


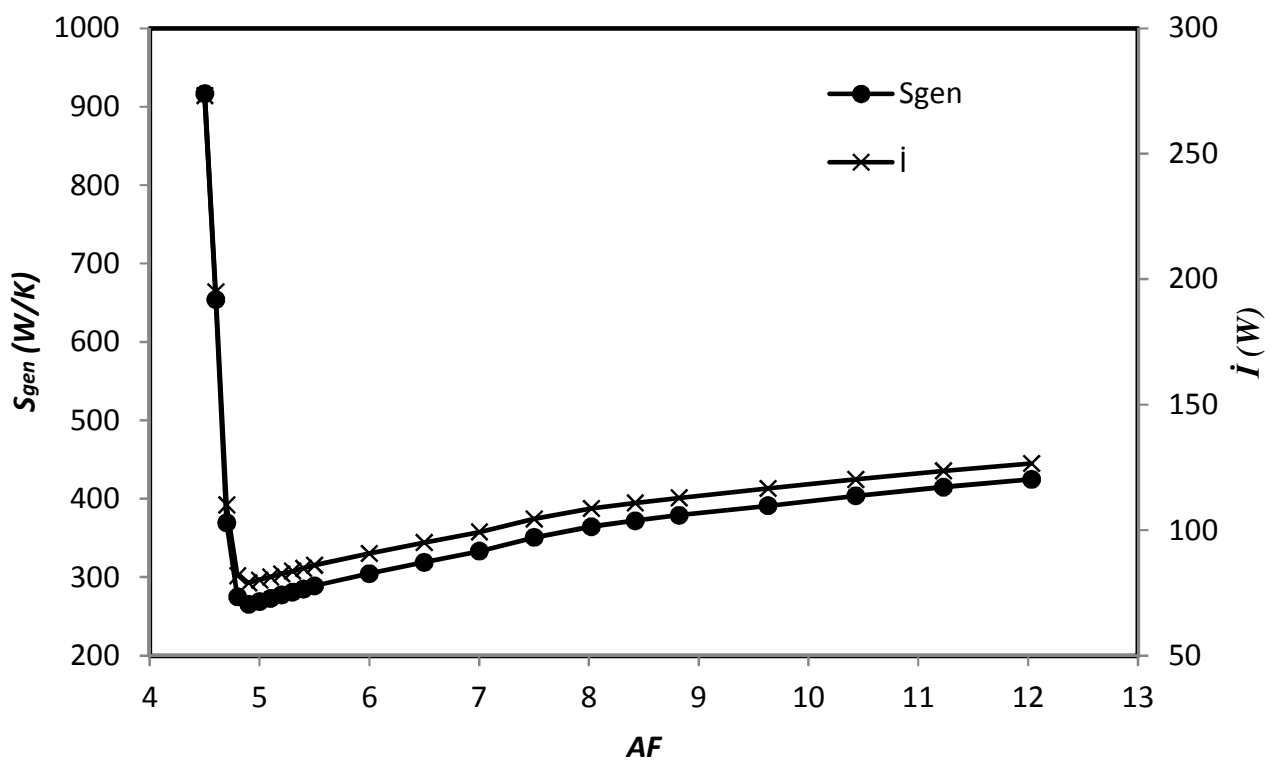

Fig. 6. Plots of the entropy generation rate and irreversibilities as functions of AF in an adiabatic combustor.

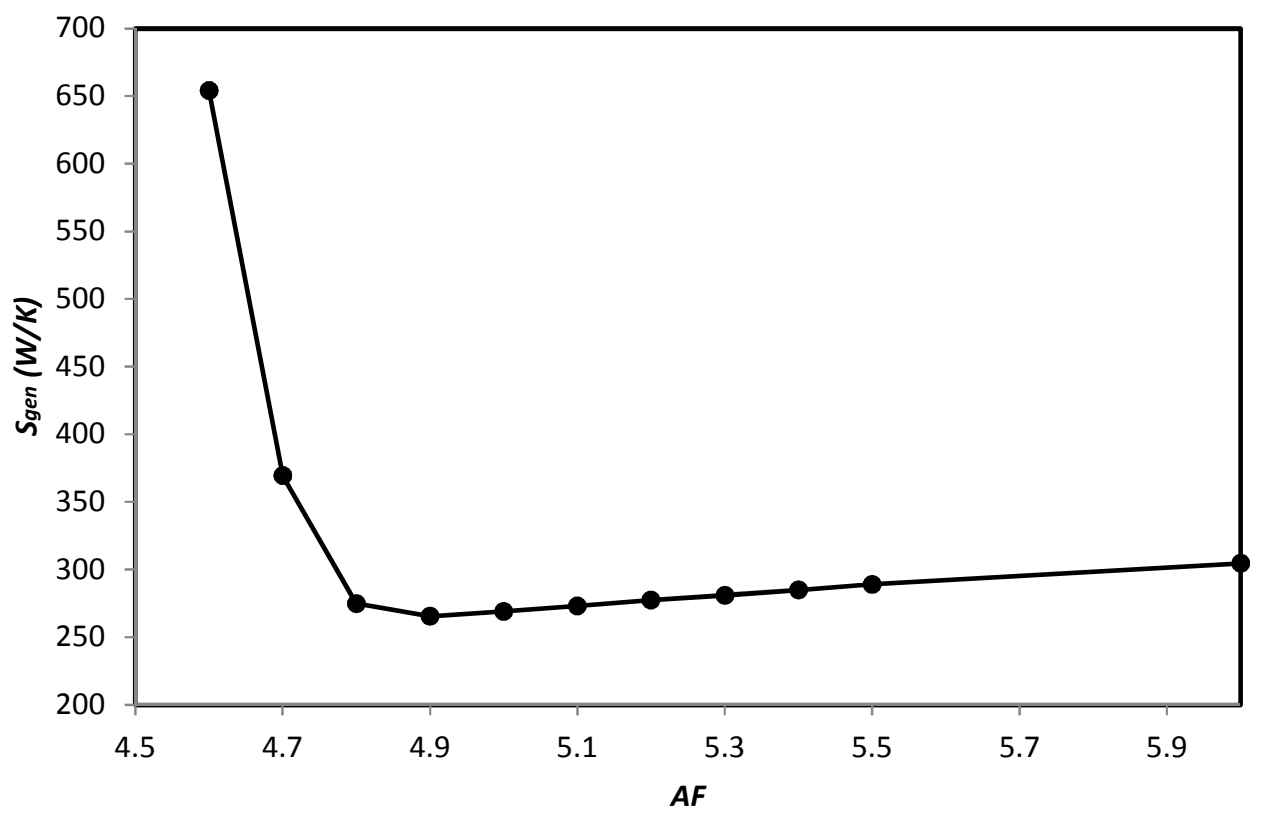

Fig. 7. A close up of the entropy generation rate profile as a function of AF in an adiabatic combustor. 
The computed values of the entropy generation rate due to the combustion process, frictional press drop, the overall entropy generation rate and the irreversibilities generated were also tabulated in Table 3 for all the plotted $\mathrm{AF}$ and corresponding equivalence ratios.

\section{Table 3}

Computed values of the entropy generation rate and irreversibilities.

\begin{tabular}{|c|c|c|c|c|c|}
\hline $\mathbf{A F}$ & Equivalence ratio & $\dot{S}_{g e n(p)}(\mathbf{W} / \mathbf{K})$ & $\dot{S}_{g e n(h)}(\mathbf{W} / \mathbf{K})$ & $\dot{S}_{g e n}(\mathbf{W} / \mathbf{K})$ & $\dot{I}(\mathbf{W})$ \\
\hline 4 & 2.005 & 0.237390033 & 3644.42 & 3644.66 & 1086.11 \\
\hline 4.1 & 1.956098 & 0.240265992 & 2824.117687 & 2824.358 & 841.6587 \\
\hline 4.2 & 1.909524 & 0.243068457 & 2036.776795 & 2037.02 & 607.0319 \\
\hline 4.3 & 1.865116 & 0.245796486 & 1544.100364 & 1544.346 & 460.2152 \\
\hline 4.4 & 1.822727 & 0.248450379 & 1242.88416 & 1243.133 & 370.4535 \\
\hline 4.5 & 1.782222 & 0.251030896 & 916.5697472 & 916.8208 & 273.2126 \\
\hline 4.6 & 1.743478 & 0.253537704 & 653.7978266 & 654.0514 & 194.9073 \\
\hline 4.7 & 1.706383 & 0.25597112 & 369.1511782 & 369.4071 & 110.0833 \\
\hline 4.8 & 1.670833 & 0.258330312 & 274.588215 & 274.8465 & 81.90427 \\
\hline 4.9 & 1.636735 & 0.260615659 & 265.0651819 & 265.3258 & 79.06709 \\
\hline 5 & 1.604 & 0.262827439 & 268.7854397 & 269.0483 & 80.17638 \\
\hline 5.1 & 1.572549 & 0.264965702 & 272.828133 & 273.0931 & 81.38174 \\
\hline 5.2 & 1.542308 & 0.26703045 & 277.0432976 & 277.3103 & 82.63848 \\
\hline 5.3 & 1.513208 & 0.269021683 & 280.6182435 & 280.8873 & 83.70441 \\
\hline 5.4 & 1.485185 & 0.270939401 & 284.5333752 & 284.8043 & 84.87169 \\
\hline 5.5 & 1.458182 & 0.272783605 & 288.6333938 & 288.9062 & 86.09404 \\
\hline 6 & 1.336667 & 0.280901916 & 304.1216374 & 304.4025 & 90.71196 \\
\hline 6.5 & 1.233846 & 0.287182364 & 318.76 & 319.05 & 95.08 \\
\hline
\end{tabular}




\begin{tabular}{llllll}
7 & 1.145714 & 0.291624947 & 332.9877197 & 333.2793 & 99.31724 \\
7.5 & 1.069333 & 0.294229666 & 350.3486205 & 350.6429 & 104.4916 \\
8.02 & 1 & 0.294988965 & 364.1874005 & 364.4824 & 108.6158 \\
8.42 & 0.952494 & 0.294220374 & 371.7057442 & 372 & 110.856 \\
8.82 & 0.909297 & 0.292275546 & 378.5330356 & 378.8253 & 112.8899 \\
9.63 & 0.832814 & 0.284734689 & 390.9738209 & 391.2586 & 116.595 \\
10.43 & 0.768936 & 0.27255259 & 403.2551109 & 403.5277 & 120.2512 \\
11.23 & 0.714159 & 0.255665558 & 414.5166439 & 414.7723 & 123.6021 \\
12.03 & 0.666667 & 0.234073594 & 424.663812 & 424.8979 & 126.6196 \\
\hline
\end{tabular}

Fig. 8 also shows the variation of entropy generation rate, but as a function of equivalence ratio. An equivalence ratio of 1 means complete combustion with theoretical amount of air, whereas an equivalence ratio above 1 signifies a rich mixture. Fig. 8 also shows that the entropy generation rate reached a minimum at an equivalence ratio of 1.64 where incomplete combustion occurs. Both Fig. 6 and Fig. 8 show that when you have an increase in richness of the reactants mixture or deficiency in air the entropy generation rate drops off gradually until minimum is reached. Then the entropy generation rate rises rapidly as the AF is decreased gradually. 


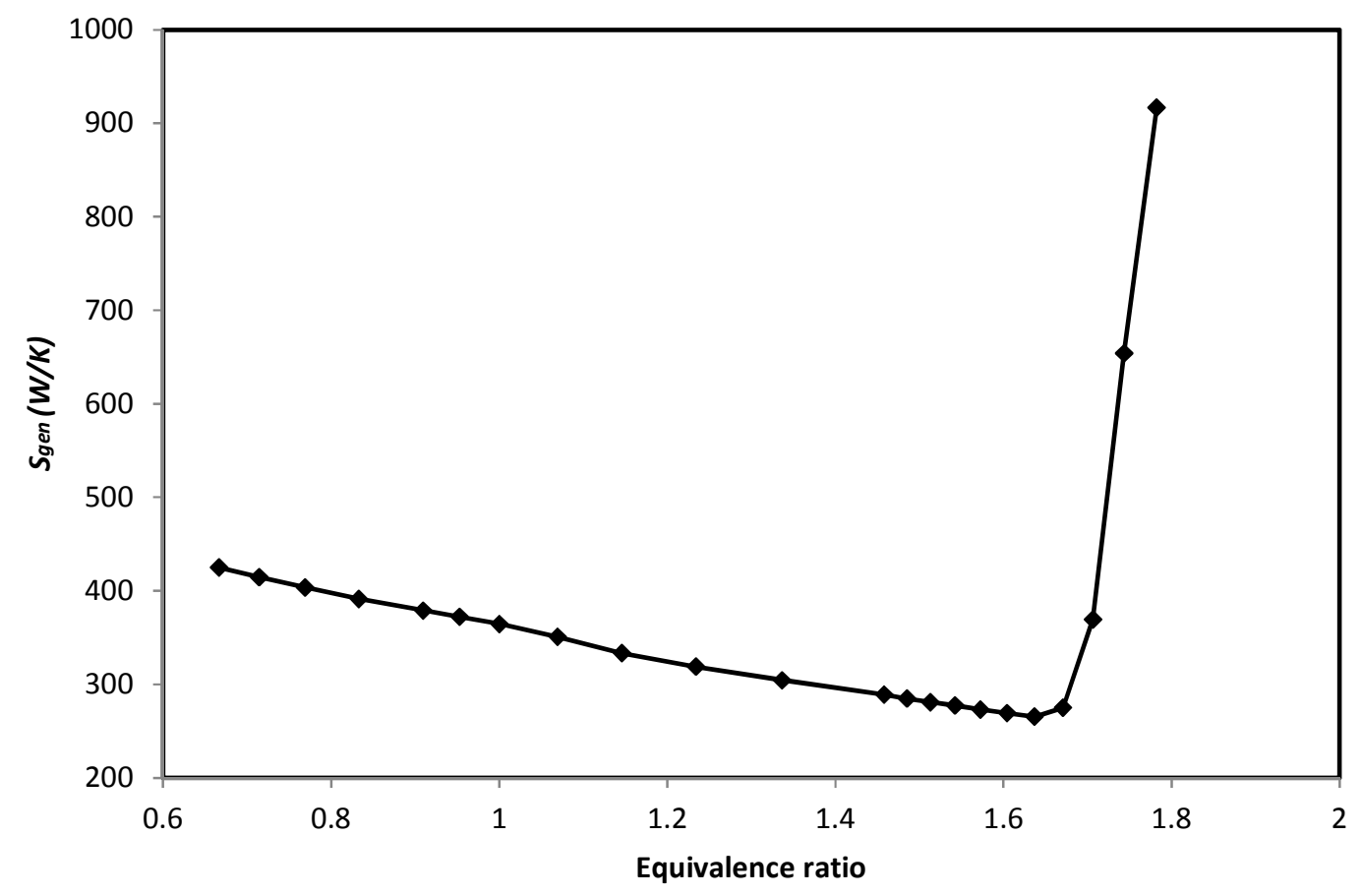

Fig. 8. Plot of entropy generation rate profile as a function of equivalence ratio in an adiabatic combustor.

The entropy generation rate was normalised with respect to the value computed when combustion occurred with theoretical amount of air $N_{R}$, and this plotted in Fig. 9. Fig. 9 shows that an AF of about 12 (Which is a 50\% excess air) resulted in a relative increase in entropy generation rate of $16.5 \%$. However an AF of 4.5 resulted in about 2.5 fold increase in entropy generation rate. Fig. 9 also shows that at an AF of 4.7 entropy was generated at the same rate as when there is complete combustion with theoretical air ratio. A similar plot for the relative entropy generation rate is plotted in Fig. 10, but as a function of equivalence ratio.

Fig. 9 and Fig. 10 also show that the minimum entropy generation rate is about $73 \%$ of the value when combustion occurred with theoretical air ratio. 


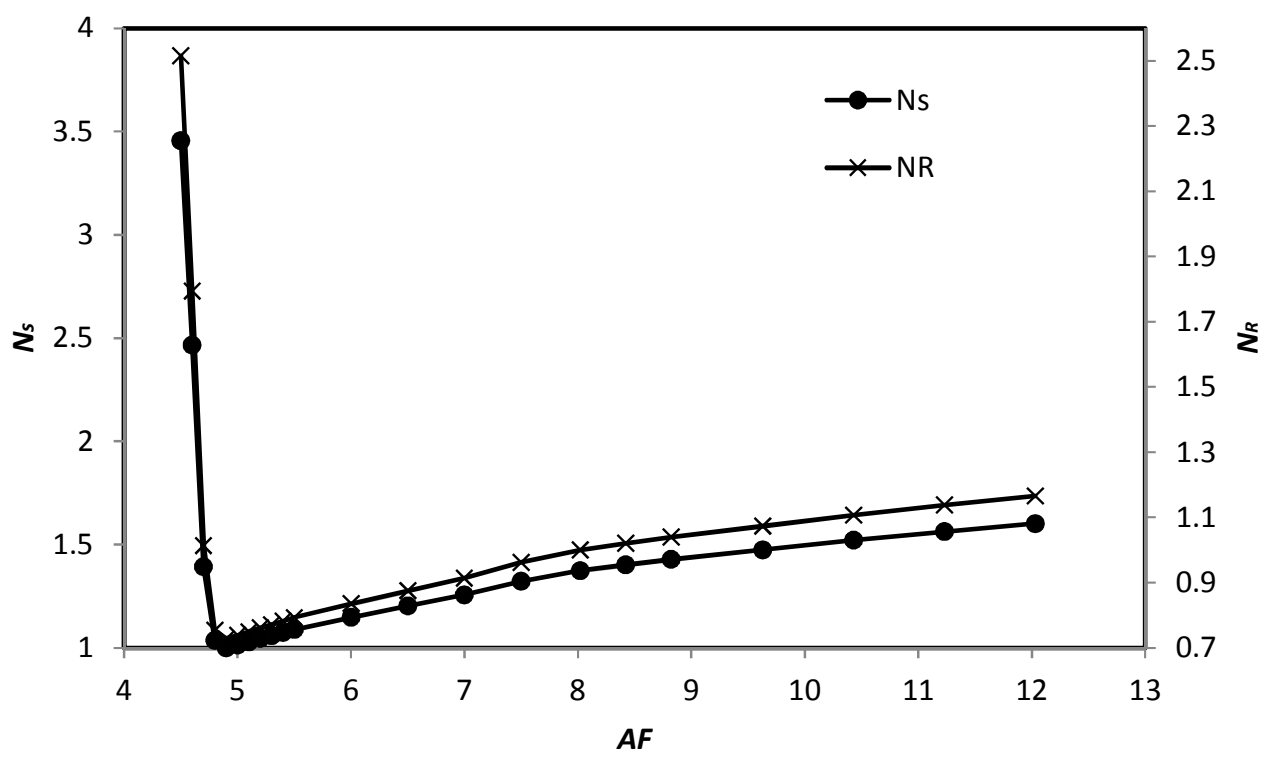

Fig. 9. Plot of entropy generation number and relative entropy generation rate as a function of $\mathrm{AF}$ in an adiabatic combustor.

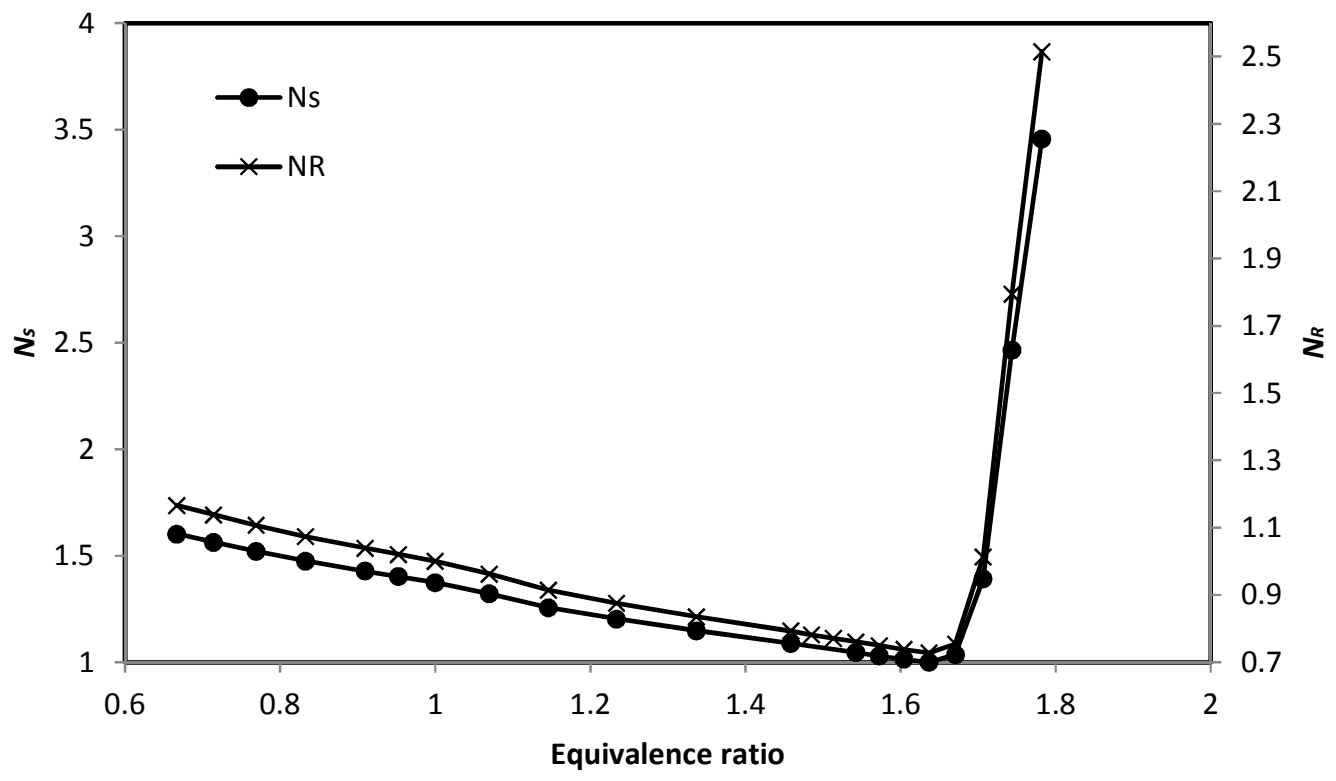

Fig. 10. Plot of entropy generation number and relative entropy generation rate as a function of equivalence ratio in an adiabatic combustor. 
However the relative entropy generation rate was also computed with respect to the minimum value as an entropy generation number, $N_{s}$, and is plotted in Fig. 9. Fig. 9 shows that the entropy generated when there is complete combustion with theoretical air ratio of 8.02 is about $37 \%$ more than the minimum rate. Combustion at an $\mathrm{AF}$ of 4.5 resulted in an entropy generation rate that is almost 3.5 times that of the minimum rate which occurred at an $\mathrm{AF}$ of 4.9. The entropy generation number was also plotted as a function of the equivalence ratio as shown in Fig. 10.

The temperature of the exiting combustion products mixture was plotted as a function of the AF as shown by Fig. 11. As expected the highest temperature is achieved when combustion occurred with theoretical air ratio of 8.02 , and it decreases as either a lean or rich mixture is combusted.

The variation of molar fraction of combustion species were plotted as a function of the AF as shown in Fig. 12. The molar fraction for $N_{2}$ was not included in the plot because it is far bigger than the others, hence it would obscure the variations in the other molar fractions, and the fact that nitrogen was assumed to be inert to the combustion process. Fig. 12 could hold a clue as why the minimum entropy generation rate occurred at an AF of 4.9. It can be seen from the figure that at about an AF of 4.9 the molar fractions of $\mathrm{H}_{2}$ and $\mathrm{H}_{2} \mathrm{O}$ are equal. This ratio also happened to be about the same point at which the molar fraction of $\mathrm{CO}_{2}$ is at its lowest for a rich mixture. The other species are negligible in comparison. A consequent effect of this is that the combined contribution to total entropy generation rate from $\mathrm{H}_{2}, \mathrm{H}_{2} \mathrm{O}$ and $\mathrm{CO}_{2}$ is the lowest at an $\mathrm{AF}$ of 4.9 than at any other AF, since at an AF of 4.9 the molar fractions that are significant other than that of $\mathrm{N}_{2}$ are those of $\mathrm{CO}_{2}, \mathrm{H}_{2} \mathrm{O}$ and $\mathrm{H}_{2}$. This then result in the lowest entropy generation rate occurring at an AF of 4.9. As mentioned in [1] the combustion model implemented in the CFD software of [32] over-predicts the presence of $\mathrm{O}_{2}$ 
. It was also mentioned in [1] that this has the effect of lowering the combustion products mixture temperature due to the presence of more species available to share in carrying the heat energy.

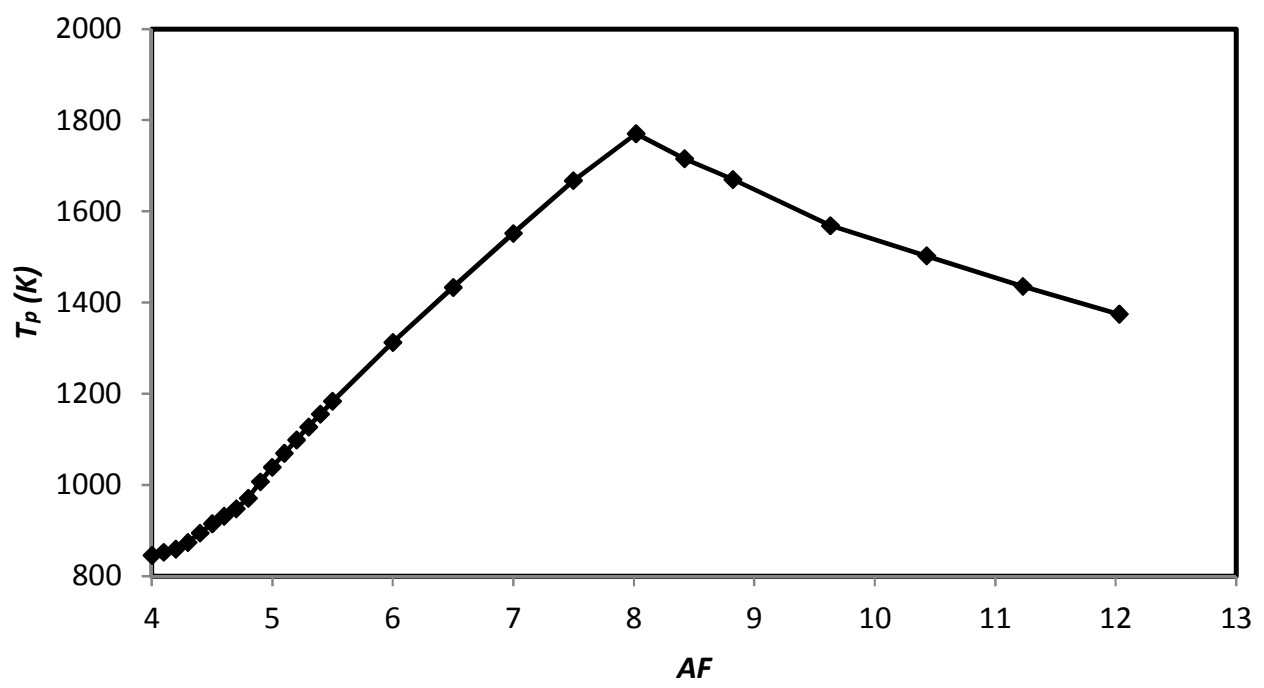

Fig. 11. Plot of combustion products mixture temperature as a function of AF in an adiabatic combustor.

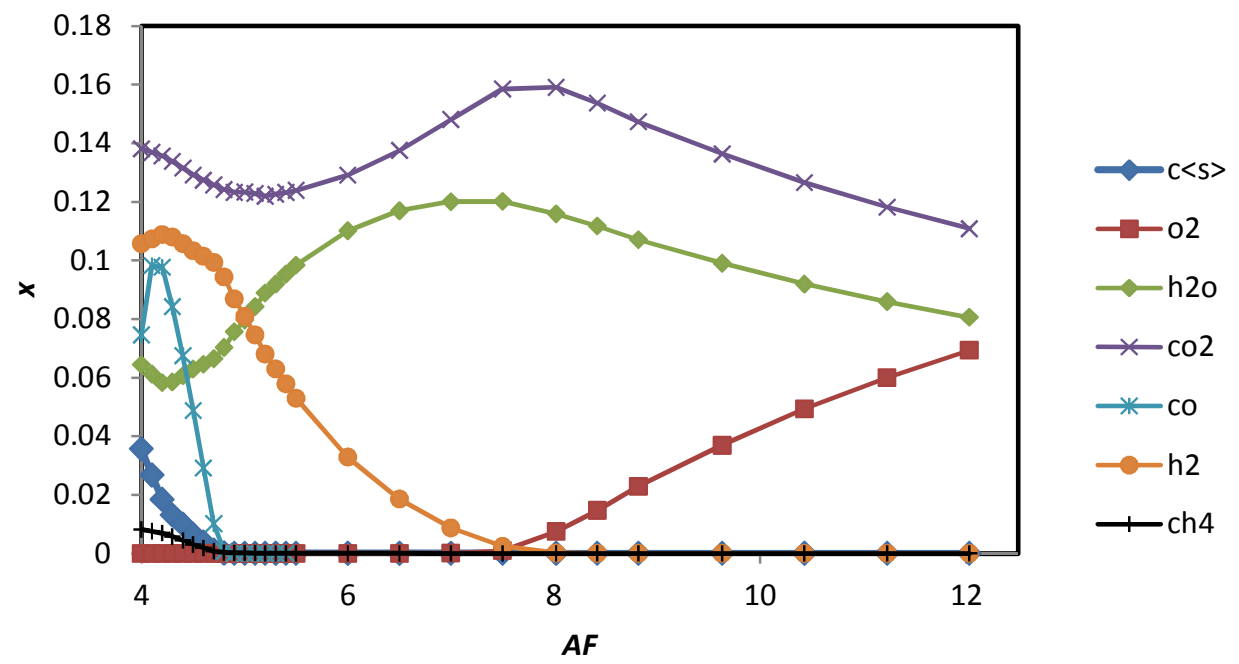

Fig. 12. Plot of variation with AF in molar fraction of combustion product species in an adiabatic combustor. 


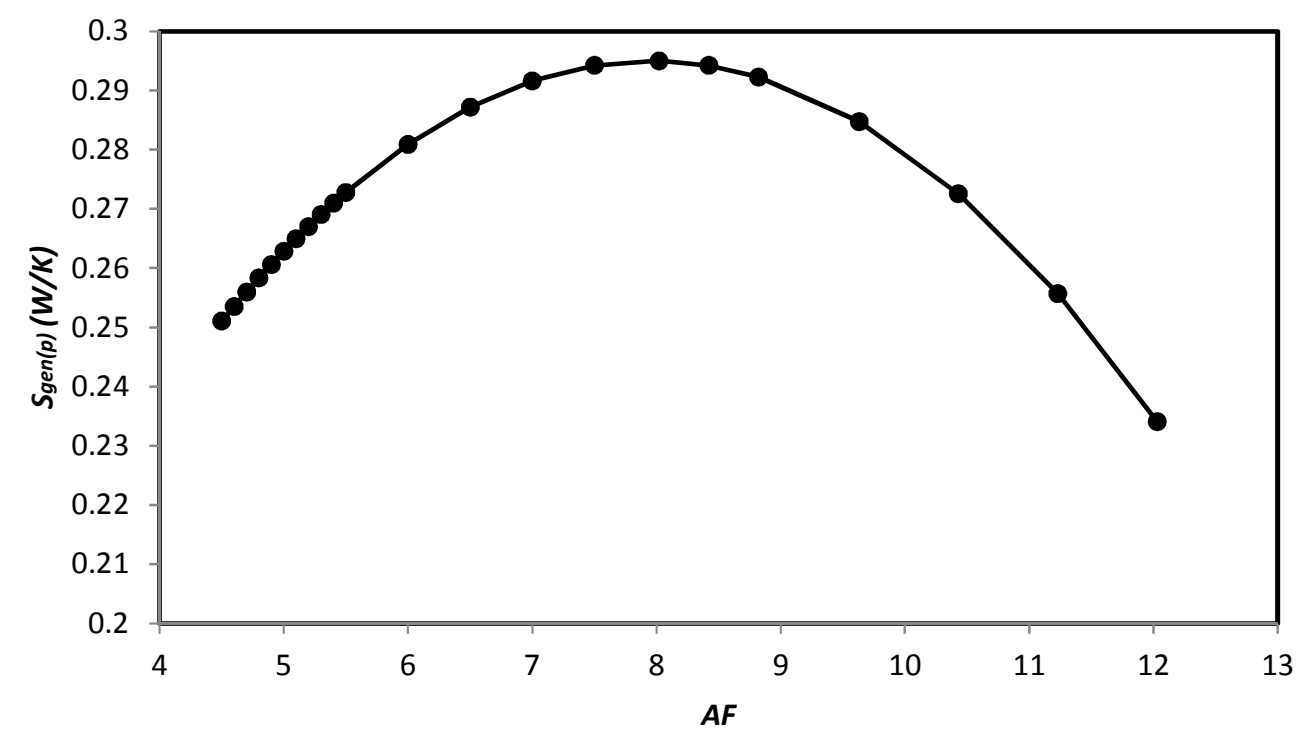

Fig. 13. Plot of entropy generate rate due to frictional pressure drop as a function of AF in an adiabatic combustor.

As mentioned earlier the entropy generation rate due to frictional pressure drop is negligible compared to that due to the combustion process. However for the geometric configuration used in this study the entropy generation rate due combustion cannot tell if the flow process is physically possible or not. For this we used the entropy generation rate due to frictional pressure drop to see where it became negative to know whether it would or not occur in the physical world. For the current geometric and flow configuration, Fig. 13 shows that the flow process is physically possible because $\dot{S}_{g e n(p)}$ is positive throughout the AF range under consideration. Because it is negligible in magnitude in comparison to the entropy generation rate due to combustion, the entropy generation rate due to frictional pressure drop was plotted on its own as a function of the AF as shown in Fig. 13. Whereas a minimum is observed for the overall entropy generation rate, Fig. 13 predicts a maximum for the frictional pressure drop entropy generation rate. The maximum value occurred at an AF of about 8 , which is almost an $\mathrm{AF}$ of 8.02, where complete combustion occurred with theoretical air ratio. Section 
plots of contours of temperature (in Kelvins) through the adiabatic combustor for the case with AF of 4.9 and 8.02 are plotted respectively in Fig. 14 and Fig. 15. From the two figures it can be seen that the average adiabatic temperatures plotted in Fig. 11 were arrived at by averaging over a temperature range at the outlet of the combustor.
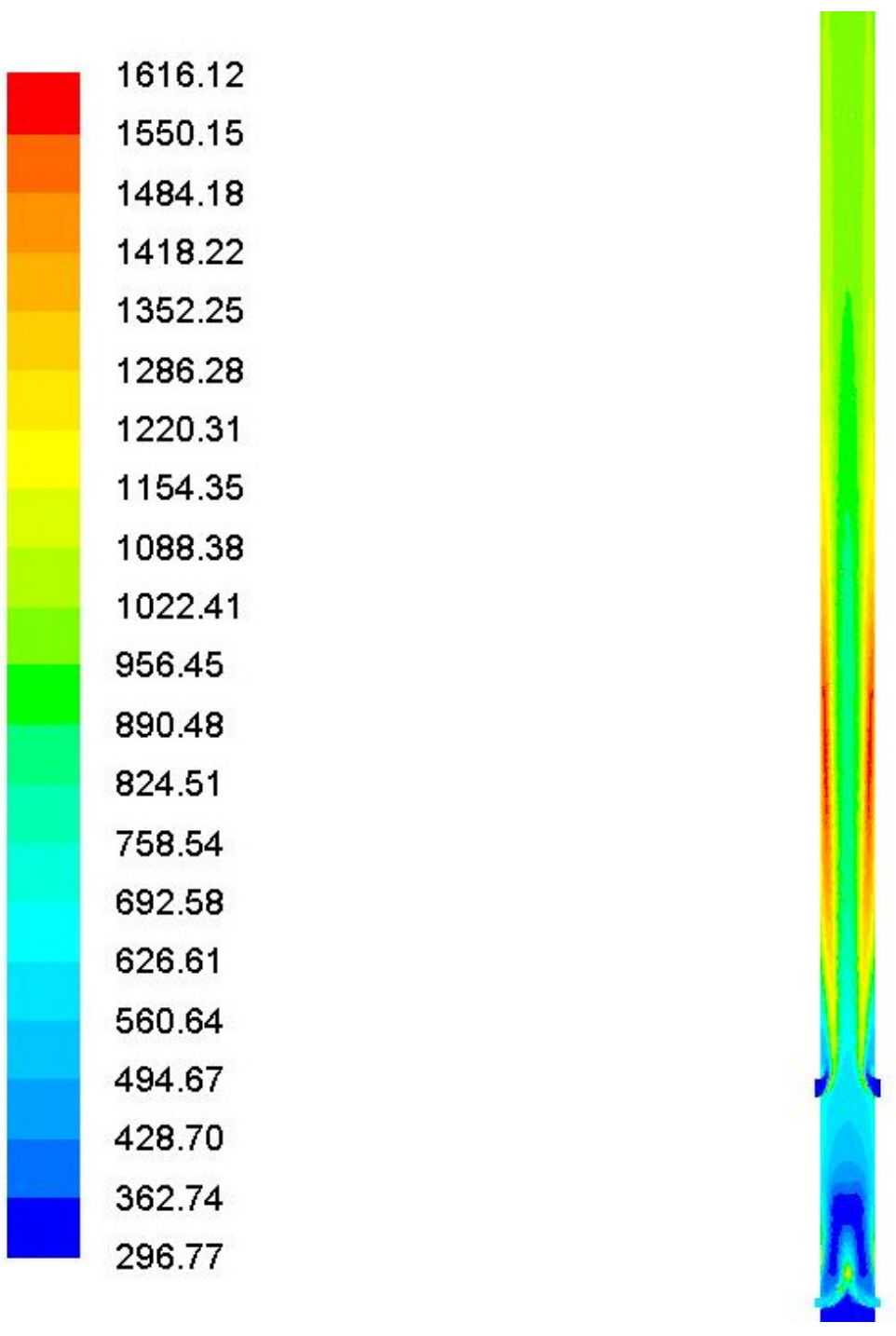

Fig. 14. Section plot of filled temperature contours (Kelvins) for the case with AF of 4.9. 

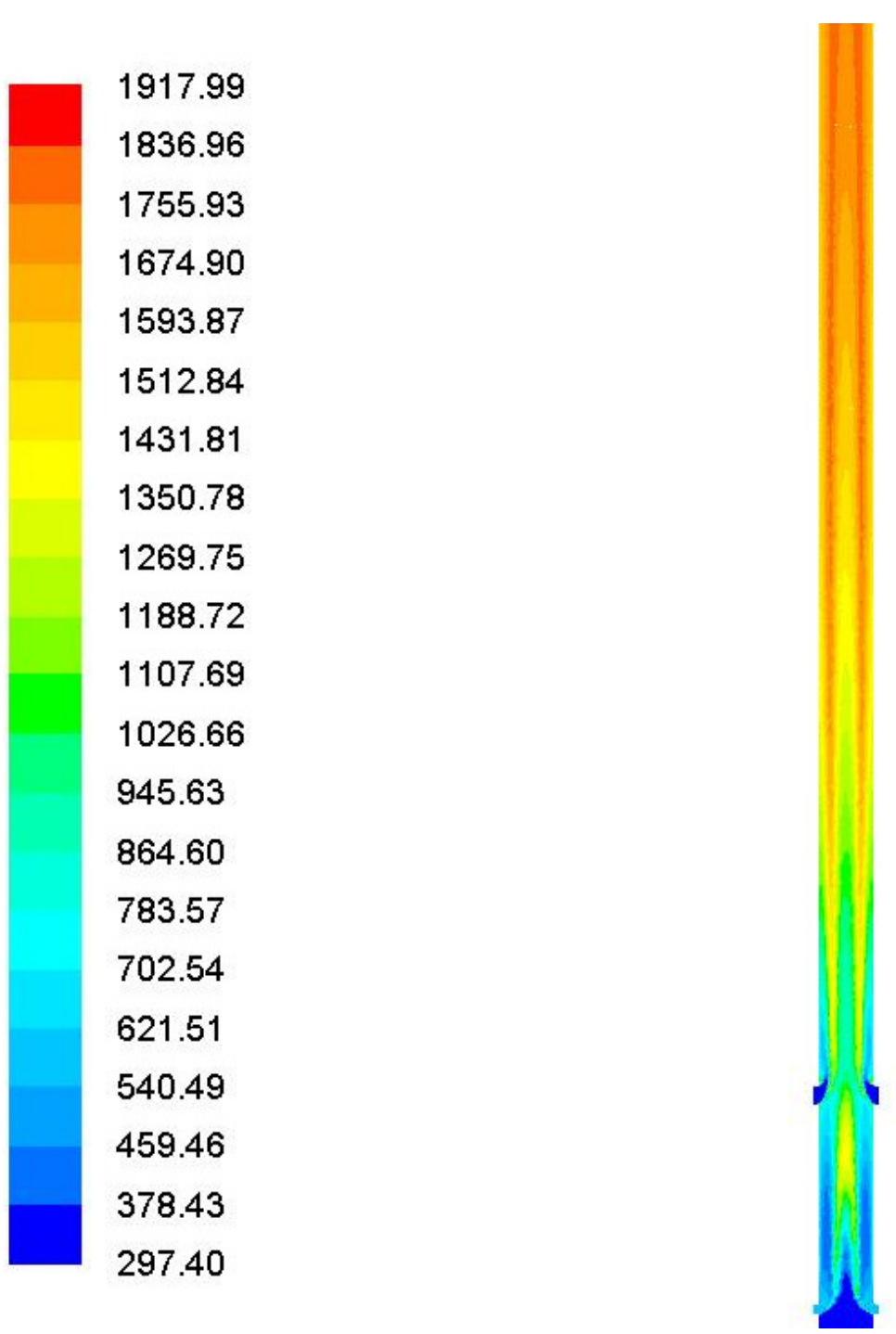

Fig. 15. Section plot of filled temperature contours (Kelvins) for the case with AF of 8.02.

\section{Conclusions}

The entropy generation rates due to the combustion and frictional pressure drop processes were analysed in order to calculate the irreversibilities generated in the adiabatic combustor. It was found that the entropy generation rate due to frictional pressure drop was negligible when compared to that due to combustion. The analysis of the irreversibilities generated during the combustion process of an adiabatic combustor with a fixed geometry was 
conducted and it was found that a minimum was reached when the Air-Fuel mass ratio was 4.9. At about this Air-Fuel mass ratio the molecular hydrogen and water vapour were at equal amounts of molar fraction and the carbon dioxide molar fraction was at its minimum for a rich mixture. This resulted the combined contribution from $\mathrm{H}_{2}, \mathrm{H}_{2} \mathrm{O}$ and $\mathrm{CO}_{2}$ to the entropy generation rate being the lowest at an $\mathrm{AF}$ of 4.9 than at any other AF; hence a minimum entropy generation rate since they have the most significant molar fractions other than $N_{2}$.

\section{Acknowledgements}

The authors would like express their appreciation to the National Research Foundation (NRF), University of Pretoria and the Council for Scientific and Industrial Research (CSIR) for the financial support and making their infrastructures available for this study.

\section{References}

[1] Baloyi J, Bello-Ochende T, Meyer JP. "The analysis of exergy destruction of a wood fired adiabatic combustor". International Conference on Applied Energy. Pretoria, South Africa, 2013.

[2] Moran MJ, Shapiro HN. Fundamentals of engineering thermodynamics. 3rd Ed., SI Version, John Wiley and Sons Inc.: Chichester, 1998.

[3] Anamalai K, Puri K. Advanced thermodynamics engineering. CRC Press Inc.: Florida, 2002.

[4] Bejan A. Advanced engineering thermodynamics. John Wiley and Sons Inc.: New York,1988. 
[5] Elfasakhany A, Tao L, espenas B, Larfeldt, Bai XS. Pulverised wood combustion in a vertical furnace: Experimental and computational analyses. Applied Energy 2013; 112: 454464.

[6] Chen W, Chen C, Hung C, Shen C, Hsu H. A comparison of gasification phenomena among raw biomass, torrefied biomass and coal in an entrained-flow reactor. Applied Energy 2013; 112: 421-430.

[7] Tran K, Luo X, Seisenbaeva G, Jirjis R. Stump torrefaction for bioenergy application. Applied energy 2013; 112: 539-546.

[8] Zhang J, Zhao Z, Zhang G, Xi Z, zhao F, Dong L, Xu G. Pilot study on jetting preoxidation fluidized bed gasification adapting to caking coal. Applied Energy 2013; 110: 276284.

[9] Bejan A. Entropy generation minimization: The method of thermodynamic optimization of finite-size systems and finite-time processes. CRC Press Inc.: Florida, 1996.

[10] Le roux WG, Bello-Ochende T, Meyer JP. Optimum performance of a small-scale open and direct solar thermal Brayton cycle at various environmental conditions and constraints. Energy 2012; 46 (1): 42-50.

[11] Mwesigye A, Bello-Ochende T, Meyer JP. Numerical investigation of entropy generation in a parabolic through receiver at different concentration ratios. Energy 2013; 53: 114-127.

[12] Le Roux WG, Bello-Ochende T, Meyer JP. Operating conditions of an open and direct solar thermal Bryaton cycle with optimised cavity receiver and recuperator. Energy 2011; 36 (10): 6027-6-36. 
[13] Kunii D, Levenspiel O. Fluidization Engineering. Stoneham: Massachusetts, 1991.

[14] Gupta AVSSKS, Reddy BV. Effect of pressure on thermal aspects in the riser column of a pressurized circulating fluidized bed. International Journal of Energy Research 2006; 30: 149-162.

[15] Han L, Wang Q, Luo Z, Rong N, Deng G. $\mathrm{H}_{2}$ rich gas production via pressurized fluidized bed gasification of sawdust with in situ $\mathrm{CO}_{2}$ capture. Applied Energy 2013; 109: $36-43$.

[16] Aisyah L, Ashman PJ, Kwong CW. Performance of coal fly-ah based oxygen carrier for the chemical looping combustion of synthesis gas. Applied Energy 2013; 109: 44-50.

[17] Aghbalou F, Badia F, Illa J. Exergetic optimization of solar collector and thermal energy storage system. International Journal of Heat and Mass Transfer 2006; 49: 1255-1263.

[18] Kousksou T, Strub F, Castaing Lasvignottes J, Jamil A, Bedecarrats JP. Second law analysis of latent thermal storage for solar system. Solar Energy Materials \& solar Cells 2007; 91: 1275-1281.

[19] Li Y, He Y, Wang Z, Xu C, Wang W. Exergy analysis of two phase change materials storage for solar thermal power with finite-time thermodynamics. Renewable Energy 2012; 39: 447-454.

[20] Jegadheeswaran S, Pohekar SD, Kousksou T. Exergy based performance evaluation of latent heat thermal storage system: A review. Renewable and Sustainable energy Reviews 2010; 14: 2580-2595. 
[21] Brandvoll O, Bolland O. "Inherent CO_2 capture using chemical looping combustion in a natural gas fired power cycle”. Proceedings of ASME TURBO EXPO: Amsterdam, The Netherlands, 2002.

[22] Srinivas T, Gupta AVSSKS, Reddy BV, Nag PK. Parametric analysis of a coal based combined cycle power plant. International Journal of Energy Research 2006; 30: 19-36.

[23] Ziebik A, stanek W. Influence of blast-furnace process thermal parameters on energy and exergy characteristics and exergy losses. International Journal of Energy Research 2006; 30: 203-219.

[24] Ziebik A, stanek W. Energy and exergy system analysis of thermal improvements of blast-furnace plants. International Journal of Energy Research 2006; 30: 101-114.

[25] Nur Izyan Z, Shuhaimi M. Exergy analysis for fuel reduction strategies in crude distillation unit. Energy 2014; 66: 891-897.

[26] Gupta AVSSKS, Reddy BV. Effect of pressure on thermal aspects in the riser column of a pressurized circulating fluidized bed. International Journal of Energy Research 2006; 30: 149-162.

[27] Cihan A, Hacihafizoglu O, Kahveci K. Energy-exergy analysis and modenization suggestions for a combined-cycle power plant. International Journal of Energy Research 2006; 30: 115-126.

[28] Bapat SM, Majali VS, Ravindranath G. Exergetic evaluation and comparison of quintuple effect evaporation units in Indian sugar industries. International Journal of Energy Research 2013; 37: 1415-1427. 
[29] Ghazikhani M, Hatami M, Ganji DD, Gorji-Bandpy M, Behravan A, Shahi G. Exergy recovery from the exhaust cooling in a DI diesel engine for BSFC reduction purposes. Energy 2014; 65: 44-51.

[30] Ghazikhani M, Hatami M, Safari B, Ganji DD. Experimental investigation of performance improving and emissions reducing in a two stroke SI engine by using ethanol additives. Propulsion and Power Research 2013; 2(4): 276-283.

[31] Ghazikhani M, Hatami M, Safari B. The effect of alcoholic fuel additives on exergy parameters and emissions in a two stroke gasoline engine. Arabic Journal of Science and Engineering 2014; 39: 2117-2125.

[32] Chintala V, Subramanian KA. Assessment of maximum available work of a hydrogen fuelled compression ignition engine using exergy analysis. Energy 2014; 67: 162-175.

[33] Jafarmadar S. Multidimensional modelling of the effect of EGR (exhaust gas recirculation) mass fraction on exergy terms in an indirect injection diesl engine. Energy 2014; 66: 305-313.

[34] Ting TW, Hung YM, Guo N. Entropy generation of nanofluid flow with streamwise conduction in microchannels. Energy 2014; 64: 979-990.

[35] www.Ansys.com; Accessed 23 January 2014

[36] Tillman DA, Rossi AJ, Kitto WD. Wood Combustion: Principles, Processes and Economics. Academic Press Inc.: New York, 1981. 